\title{
Penetapan Kadar Klorofil dan Karotenoid Daun Sawi (Brassica) Menggunakan Metode Spektrofotometri UV-Vis
}

\author{
Eni Kartika Sari ${ }^{* a}$, Sholihatil Hidayati ${ }^{b}$ \\ Analis Farmasi, Akademi Analis Farmasi Al Islam Yogyakarta, Yogyakarta, 55142, Indonesia \\ Prodi Farmasi, Stikes dr. Soebandi, Jember, Jawa Timur, 68111, Indonesia
}

INFO ARTIKEL

Diterima 15 Mei 2020

Disetujui 23 Juni 2020

Key word:

Penetapan Kadar

Klorofil

Karotenoid

Kata kunci:

Determination of level

Chlorophyll

Carotenoid

${ }^{*}$ e-mail:

kartikasarieni83@gmail.com

*Telp:+6281804314893

\author{
A BSTRACT
}

Chlorophyll and carotenoids are antioxidant compounds that are very potential. Both of these compounds are found in many vegetables. This research aims to determine the levels of chlorophyll and carotenoids in mustard (Brassica) leaves. There were three types of mustard leaves tested, namely greens mustard (Brassica rapa I.), white mustard (Brassica juncea L.) and pakcoy (Brassica rapa L.). Analysis of samples by the UV-Vis Spectrophotometry method. The results of the measurement of chlorophyll levels showed that pakcoy (Brassica rapa L.) had the highest chlorophyll level which was $86,76 \mathrm{mg} / \mathrm{g}$. While the lowest chlorophyll level is found in the type of white mustard which is equal to $0,75 \mathrm{mg} / \mathrm{g}$. From the three of the mustard tested, green mustard (Brassica rapa I.) and pakcoy (Brassica rapa L.) were mustard types that contained high carotenoids in the amount of 50,4 $\mathrm{mg} / \mathrm{g}$ and 198,04 mg/g. While the type of white mustard (Brassica juncea L.) has the lowest carotenoid content for all preparations.

\begin{abstract}
A BSTRAK
Klorofil dan karotenoid merupakan senyawa antioksidan yang sangat potensial. Kedua senyawa ini banyak ditemukan pada tanaman sayuran. Penelitian ini bertujuan untuk menentukan kadar klorofil dan karotenoid pada daun sawi (Brassica). Ada tiga jenis daun sawi yang diuji yaitu sawi hijau (Brassica rapa I.), sawi putih (Brassica juncea L.) dan pakcoy (Brassica rapa L.). Analisis sampel dengan metode Spektrofotometri Uv-Vis. Hasil pengukuran kadar klorofil menunjukkan bahwa sawi jenis pakcoy (Brassica rapa L.) memiliki kadar klorofil paling tinggi yaitu sebesar $86,76 \mathrm{mg} / \mathrm{g}$. Sedangkan kadar klorofil terendah terdapat pada jenis sawi putih yaitu sebesar 0,75 mg/g. Dari ketiga sawi yang diuji, sawi hijau (Brassica rapa I.) dan pakcoy (Brassica rapa L.) merupakan jenis sawi yang mengandung karotenoid yang tinggi yaitu sebesar 50,4 mg/g dan 198,04 mg/g . Sedangkan jenis Sawi Putih (Brassica juncea L.) memiliki kandungan karotenoid terendah untuk semua sediaan.
\end{abstract}

\section{Pendahuluan}

Sawi adalah sekelompok tumbuhan dari marga Brassica yang banyak dimanfaatkan daun atau bunganya sebagai bahan pangan (sayuran). Sawi terdiri dari beberapa spesies yang memiliki kemiripan satu dengan lainnya. Di Indonesia penyebutan sawi biasanya mengacu pada sawi hijau (Brassica rapa I.) merupakan kelompok parachinensis yang disebut juga sawi bakso, caisim, atau caisin. Selain itu, terdapat pula sawi putih (Brassica juncea L.), jenis ini umumnya dibuat sup atau diolah menjadi asinan. Sedangkan sawi jenis pakcoy (Brassica rapa L.) merupakan jenis sayuran daun kerabat sawi yang mulai dikenal pula dalam dunia boga Indonesia.

Sayuran dari keluarga Brassicaceae adalah sumber fitokimia bioaktif yang sangat baik dan dapat mengurangi risiko penyakit kronis [1]. Asupan sayuran sawi yang tinggi mengurangi risiko penyakit kronis yang berkaitan dengan usia, seperti penyakit kardiovaskular dan penyakit degeneratif lainnya dan beberapa jenis kanker [2]. Hal ini berhubungan dengan 
kemampuan antioksidan dari kandungan senyawa sayuran sawi [3]. Sawi mengandung beberapa senyawa diantaranya klorofil, karotenoid, flavonoid dan fenolik [1].

Klorofil dan karotenoid yang terkandung dalam sawi sangat potensial untuk dikembangkan sebagai suplemen dalam penanganan penyakit degeneratif dan kanker. Ketersediaan klorofil yang tinggi di alam serta khasiat biologis yang dimilikinya, menjadi peluang untuk dikembangkan sebagai bahan suplemen pangan atau pangan fungsional. Oleh karena itu, penting untuk dilakukan penetapan kandungan klorofil dan karotenoid dalam sayuran sawi. Penetapan kadar klorofil dan karotenoid daun sawi (Brassica) dilakukan dengan menggunkan metode spektrofotometri UV-Vis.

\section{Bahan dan Metode}

Penelitian ini dilakukan di Laboratorium Kimia Analisis Akademi Analis Farmasi Al Islam Yogyakarta. Alat yang diperlukan yaitu: Spektrofotometri UV-Vis dan alat gelas laboratorium. Sedangkan bahan yang diperlukan: aseton $80 \%$, aquades, sampel sawi yang diperoleh dari Pasar Giwangan Yogyakarta berupa sawi hijau (Brassica rapa I.), sawi putih (Brassica juncea L.), dan pakcoy (Brassica rapa L.).

Cara Kerja yang dilakukan adalah persiapan alat dan bahan, kemudian preparasi sampel. Preparasi sampel kering dilakukan dengan memotong sampel kemudian di jemur di bawah sinar matahari hingga mongering dan kadar airnya berkurang. Setelah itu, sebanyak 1 gram sampel dimaserasi selama 72 jam menggunakan aseton $80 \%$. Setelah itu sampel basah dan kering diukur kadar klorofil serta karotenoidnya dengan Metode Spektrofotometri UV-Vis pada $\lambda 663 ; 645 ; 480$ $\mathrm{nm}$. Kadar klorofil dan karotenoid dihitung dengan rumus berikut [7]:

\footnotetext{
a. Kadar klorofil

$=\left(22,7^{*} \mathrm{OD}_{663}+2,69^{*} \mathrm{OD}_{645}\right)+\left(12,9 * \mathrm{OD}_{645}-4,68 * \mathrm{OD}_{663}\right)$

b. Kadar karotenoid

$=\underline{\left(\mathrm{A}_{480}+0,114 \times \mathrm{A}_{663}-0,630 \times \mathrm{A}_{645}\right) \times \mathrm{V} \times 10^{3}}$ $112,5 \times \mathrm{W}$

$1 \mu \mathrm{mol} / \mathrm{L}=27,25 \mathrm{mg} / \mathrm{L}$
}

Ket :

A480 = absorbansi pada panjang gelombang $480 \mathrm{~nm}$

A645 = absorbansi pada panjang gelombang $645 \mathrm{~nm}$

A663 = absorbansi pada panjang gelombang $663 \mathrm{~nm}$

$\mathrm{V}=$ volume ekstrak $(\mathrm{mL})$,

$\mathrm{W}=$ berat sampel $(\mathrm{g})$

\section{Hasil dan Pembahasan}

Preparasi sampel diawali dengan membuat larutan Aseton 80\%. Larutan ini nantinya digunakan sebagai pelarut untuk maserasi sampel Sawi Hijau (Brassica rapa I), Sawi Putih (Brassica. Juncea L.), dan Sawi Pakcoy (Brassica rapa L.).

Prosedur selanjutnya adalah penimbangan sampel Sawi Hijau (Brassica rapa I.), Sawi Putih (Brassica juncea L.), dan Sawi Pakcoy (Brassica rapa L.) baik sediaan basah maupun kering menggunakan timbangan analitik. Hasil penimbangan sampel terlihat pada tabel 1 berikut ini:.

Tabel 1. Berat Sampel

\begin{tabular}{llll}
\hline Sampel & $\begin{array}{l}\mathrm{Q} \\
\text { (gram) }\end{array}$ & Sampel & $\begin{array}{l}\mathrm{Q} \\
\text { (gram) }\end{array}$ \\
\hline AB1 & 0,1000 & AK1 & 0,1000 \\
AB2 & 0,1000 & AK2 & 0,1003 \\
AB3 & 0,1001 & AK3 & 0,1002 \\
BB1 & 0,1001 & BK1 & 0,0999 \\
BB2 & 0,1000 & BK2 & 0,0999 \\
BB3 & 0,1001 & BK3 & 0,0999 \\
CB1 & 0,0999 & CK1 & 0,1001 \\
CB2 & 0,1001 & CK2 & 0,1001 \\
CB3 & 0,1001 & CK3 & 0,1000 \\
\hline
\end{tabular}

Keterangan :

$\mathrm{Q}=$ Berat Sampel B = Basah $\mathrm{K}=$ Kering

A = Sawi Hijau

$\mathrm{B}=$ Sawi Putih

$\mathrm{C}=$ Sawi Packoy

1,2,3 = Pengulangan Sampel

Setelah penimbangan sampel masukkan aseton $80 \%$ kedalam tabung reaksi lalu diamkan selama 3 hari, dimana proses ini disebut maserasi. Aseton dibuat sebagai pelarut karena dapat melarutkan klorofil dan karotenoid yang bersifat polar, sesuai prinsip "Like Dissolve Like". Setelah maserasi ekstrak 
sawi $A, B$, dan $C$ disaring sehingga diperoleh cairan beningnya. Sampel A, B dan C kemudian di analisis dengan spektrofotometri UV-Vis pada panjang gelombang $663,645,480$ $\mathrm{nm}$.

Hasil pengukuran absorbansi sawi A, B, dan C. Pengujian kadar klorofil dan karotenoid dimulai dengan mencari absorbansi dari masing-masing jenis daun sawi yang dianalisis. Tercatat hasil absorbansi dari daun sawi A, B dan C seperti tabel 2 berikut.

Tabel 2. Hasil Pengukuran Absorbansi sawi A,

\begin{tabular}{|c|c|c|c|c|c|c|c|}
\hline \multicolumn{8}{|c|}{ B dan C } \\
\hline \multirow{3}{*}{ Sampel } & \multicolumn{3}{|c|}{ Panjang Gelombang } & \multirow{3}{*}{ Sampel } & \multicolumn{3}{|c|}{ Panjang Gelombang } \\
\hline & 663 & 645 & 480 & & 663 & 645 & 480 \\
\hline & $(\mathrm{nm})$ & $(\mathrm{nm})$ & $(\mathrm{nm})$ & & $(\mathrm{nm})$ & $(\mathrm{nm})$ & $(\mathrm{nm})$ \\
\hline AB1 & 0,858 & 0,344 & 0,59 & AK1 & 3 & 1,57 & 2,526 \\
\hline AB2 & 0,850 & 0,343 & 0,612 & AK2 & 3 & 1,57 & 2,528 \\
\hline $\mathrm{AB} 3$ & 0,978 & 0,398 & 0,707 & AK3 & 3 & 1,49 & 2,302 \\
\hline BB1 & 0,031 & 0,014 & 0,031 & BK1 & 0,041 & 0,024 & 0,065 \\
\hline BB2 & 0,029 & 0,015 & 0,034 & BK2 & 0,036 & 0,019 & 0,073 \\
\hline BB3 & 0,033 & 0,019 & 0,034 & BК3 & 0,036 & 0,021 & 0,065 \\
\hline CB1 & 0,458 & 0,188 & 0,324 & CK1 & 3 & 1,768 & 3 \\
\hline CB2 & 0,589 & 0,250 & 0,420 & CK2 & 3 & 1,989 & 3 \\
\hline CB3 & 0,459 & 0,188 & 0,369 & СК3 & 3 & 2,098 & 3 \\
\hline
\end{tabular}

Berdasarkan Tabel 2 di atas, dapat dilihat bahwa nilai absorbansi tertinggi terletak pada daun sawi dalam sediaan kering. Hal tersebut dimungkinkan karena sediaan kering memiliki kadar air yang relatif rendah dibandingkan dengan sediaan basah. Jenis pengeringan yang digunakan adalah pengeringan alami atau dengan bantuan sinar matahari. Metode pengeringan ini dipilih dikarenakan sesuai untuk pengeringan bahan organik yang tidak membutuhkan suhu pengeringan tinggi sehingga tidak akan merusak zat aktif di dalamnya. Hal tersebut dapat terlihat dari nilai absorbansi maksimum yang muncul sebesar 3. Nilai absorbansi tertinggi untuk sediaan basah terdapat pada jenis Sawi Hijau (Brassica rapa I.) sebesar 0,978 dan untuk nilai absorbansi terendah 0,014 terdapat pada jenis Sawi Putih ( B. Juncea L.).

Daun sawi memiliki pigmen warna hijau menandakan bahwa daun tersebut memiliki kandungan klorofil [4].Klorofl dan karotenoid merupakan pigmen fotosintetik yang terdapat pada sayuwan [5]. Kedua senyawa ini memiliki peran penting dalam penanganan penyakit yang berhubungan dengan stress oksidatif, sepeti kanker, penyakit kardiovaskuler dan penyakit kronik lain [6]. Di bawah ini hasil perhitungan kadar klorofil dari ketiga jenis daun sawi yang diuji (tabel 3).

Tabel 3. Hasil Kadar Klorofil Sawi A, B, dan C

\begin{tabular}{cccccc}
\hline Sampel & $\begin{array}{c}\text { Klorofil } \\
(\mathrm{mg} / \mathrm{g})\end{array}$ & Sampel & $\begin{array}{r}\text { Klorofil } \\
(\mathrm{mg} / \mathrm{g})\end{array}$ & Sampel & $\begin{array}{r}\text { Klorofil } \\
(\mathrm{mg} / \mathrm{g})\end{array}$ \\
\hline AB1 & 20,82 & BB1 & 0,77 & CB1 & 11,18 \\
AB2 & 20,66 & BB2 & 0,75 & CB2 & 14,51 \\
AB3 & 23,82 & BB3 & 0,89 & CB3 & 11,20 \\
AK1 & 78,53 & BK1 & 1,11 & CK1 & 81,62 \\
AK2 & 78,53 & BK2 & 0,94 & CK2 & 85,06 \\
AK3 & 77,28 & BK3 & 0,97 & CK3 & 86,76 \\
\hline
\end{tabular}

Hasil pengukuran kadar klorofil menunjukkan bahwa sayuran sawi jenis Pakcoy (Brassica rapa L.) memiliki kadar klorofil paling tinggi yaitu sebesar $86,76 \mathrm{mg} / \mathrm{g}$. kadar klorofil terendah terdapat pada jenis Sawi Putih (Brassica juncea L.) yaitu sebesar $0,75 \mathrm{mg} / \mathrm{g}$. Hasil penelitian tersebut sesuai dengan penelitian sebelumnya yang menunjukkan bahwa kadar klorofil sawi sekitar 0,383 - 2,356 $\mathrm{mg} / \mathrm{g}$, pada sampel Sawi Putih (Brassica juncea L.) [7].

Selain klorofil, karotenoid juga sangat bermanfaat bagi tubuh manusia. Karotenoid dikenal sebagai prekusor vitamin A (beta karoten) yang memiliki efek protektif terhadap sel kanker, penyakit jantung, mata, antioksidan dan regulator sistem imun dalam tubuh [8]. Selain itu, $\beta$-Karoten mampu melindungi kulit dari efek berbahaya sinar UV dengan mencegah pembentukan oksigen reaktif spesies dan memiliki sifat anti-inflamasi [9]. Berikut merupakan hasil perhitungan kadar karotenoid dalam beberapa jenis daun sawi yang tersaji pada tabel 4 . 
Tabel 4. Hasil Penetapan Kadar Karotenoid

\begin{tabular}{crcrcr}
\multicolumn{6}{c}{ Sawi A, B, dan C } \\
Sampel & $\begin{array}{c}\text { Karotenoid } \\
(\mathrm{mg} / \mathrm{g})\end{array}$ & Sampel & $\begin{array}{c}\text { Karotenoid } \\
(\mathrm{mg} / \mathrm{g})\end{array}$ & Sampel & $\begin{array}{c}\text { Karotenoid } \\
(\mathrm{mg} / \mathrm{g})\end{array}$ \\
\hline $\mathrm{AB} 1$ & 41,86 & BB1 & 2,22 & $\mathrm{CB} 1$ & 22,84 \\
$\mathrm{AB} 2$ & 43,73 & $\mathrm{BB} 2$ & 2,4 & $\mathrm{CB} 2$ & 29,24 \\
$\mathrm{AB} 3$ & 50,4 & $\mathrm{BB} 3$ & 2,2 & $\mathrm{CB} 3$ & 26,84 \\
$\mathrm{AK} 1$ & 165,98 & $\mathrm{BK} 1$ & 4,8 & $\mathrm{CK} 1$ & 198,04 \\
$\mathrm{AK} 2$ & 167,11 & $\mathrm{BK} 2$ & 5,77 & $\mathrm{CK} 2$ & 185,6 \\
$\mathrm{AK} 3$ & 151,55 & BK3 & 4,8 & CK3 & 179,55 \\
\hline
\end{tabular}

Terlihat pada tabel 4, kandungan karotenoid dalam daun sawi sediaan basah tertinggi diperoleh pada jenis Sawi Hijau (Brassica rapa I.) sebesar $50,4 \mathrm{mg} / \mathrm{g}$ dan terendah 2,22 mg/g Sawi Putih (Brassica Juncea L.). Kadar karotenoid sediaan kering tertinggi sebesar 198,04 mg/g pada Pakcoy (Brassica rapa L.), dan 4,8 mg/g untuk Sawi Putih ( B. Juncea L.) dengan kadar karotenoid terendah. Dari hasil tersebut maka dapat disimpulkan bahwa jenis Sawi Hijau (Brassica rapa I.), Sawi Pakcoy (Brassica rapa L.) merupakan jenis sawi yang mengandung karotenoid yang tinggi. Sedangkan jenis Sawi Putih ( Brassica juncea L.) memiliki kandungan karotenoid terendah untuk semua sediaan.

\section{Kesimpulan}

Hasil pengukuran kadar klorofil menunjukkan bahwa sayuran sawi jenis Pakcoy (Brassica rapa L.) memiliki kadar klorofil paling tinggi yaitu sebesar $86,76 \mathrm{mg} / \mathrm{g}$. Sedangkan kadar klorofil terendah terdapat pada jenis Sawi Putih yaitu sebesar $0,75 \mathrm{mg} / \mathrm{g}$.

Dari ketiga sawi yang diuji, Sawi Hijau (Brassica rapa I.), Sawi Pakcoy (Brassica rapa L.) merupakan jenis sawi yang mengandung karotenoid yang tinggi. Sedangkan jenis Sawi Putih (Brassica Juncea L.) memiliki kandungan karotenoid terendah untuk semua sediaan..

\section{Daftar Pustaka}

1. dos Reis, L. C. R.; de Oliveira, V. R.; Hagen, M. E. K.; Jablonski, A.; Flôres, S. H.; de Oliveira Rios, A., Carotenoids, flavonoids, chlorophylls, phenolic compounds and antioxidant activity in fresh and cooked broccoli (Brassica oleracea var. Avenger) and cauliflower (Brassica oleracea var. Alphina F1). LWTFood Science and Technology 2015, 63, (1),
177-183.

2. Soengas, P.; Cartea, M.; Francisco, M.; Sotelo, T.; Velasco, P., New insights into antioxidant activity of Brassica crops. Food chemistry 2012, 134, (2), 725-733.

3. Verkerk, R.; Schreiner, M.; Krumbein, A.; Ciska, E.; Holst, B.; Rowland, I.; De Schrijver, R.; Hansen, M.; Gerhäuser, C.; Mithen, R., Glucosinolates in Brassica vegetables: the influence of the food supply chain on intake, bioavailability and human health. Molecular nutrition $\mathcal{E}$ food research 2009, 53, (S2), S219-S219.

4. Durga, D.; Banu, N., Study of antioxidant activity of chlorophyll from some medicinal plants. Paripex-Indian Journal of Research 2015, 4, (2), 2250-1991.

5. Žnidarčič, D.; Ban, D.; Šircelj, H., Carotenoid and chlorophyll composition of commonly consumed leafy vegetables in Mediterranean countries. Food chemistry 2011, 129, (3), 1164-1168.

6. Sangeetha, R. K.; Baskaran, V., Carotenoid composition and retinol equivalent in plants of nutritional and medicinal importance: Efficacy of $\beta$-carotene from Chenopodium album in retinol-deficient rats. Food Chemistry 2010, 119, (4), 15841590.

7. Iriyani, D.; Nugrahani, P., Kandungan klorofil, karotenoid, dan vitamin c beberapa jenis sayuran daun pada pertanian periurban di Kota Surabaya. Jurnal Matematika Sains dan Teknologi 2014, 15, (2), 84-90.

8. Kurniawan, M.; Izzati, M.; Nurchayati, Y., Kandungan klorofil, karotenoid, dan vitamin $C$ pada beberapa spesies tumbuhan akuatik. Anatomi Fisiologi 2010, 18, (1), 28-40.

9. Gumolung, D., Analisis beta karoten dari ekstrak jonjot buah labu kuning (Cucurbita moschata). Fullerene Journal of Chemistry 2017, 2, (2), 69-71. 